\title{
A qualitative study exploring socio-economic differences in parental lay knowledge of food and health: implications for public health nutrition
}

\author{
John Coveney* \\ The Department of Public Health, Flinders University, Box 2100, Adelaide, SA 5001, Australia
}

Submitted 23 February 2004: Accepted 29 September 2004

\begin{abstract}
Background: The role played by lay knowledge in understanding health inequalities has received increased interest recently. Very little is known, however, about how lay knowledge of food and health varies across social class. The present exploratory study compared and contrasted ways in which people from different social backgrounds draw on and use different forms of lay knowledge about food and health.

Method: Parents from 40 families were recruited from two socio-economically different suburbs (20 families from each suburb). In-depth interviews were conducted with the mother and father in each family to examine lay knowledge about food and health. All interviews were transcribed and coded for specific themes. Responses from each suburb were compared and contrasted.

Results: Different forms of lay knowledge about food and health were noted, especially concerning children's eating habits. Parents in the high-income suburb were more likely to discuss food and health in technical terms informed by contemporary nutritional or medical priorities. Parents in the low-income suburb did not share this discourse, but instead were more likely to discuss food in terms related to children's outward appearance or functional capacity.

Conclusions and implications: The research highlights differences in lay knowledge about food and health across social class. It emphasises the need for public health nutrition policy-makers and practitioners to pay attention to lay knowledge on its own terms, rather than attempting to educate from predetermined assumptions, principles and standards.
\end{abstract}

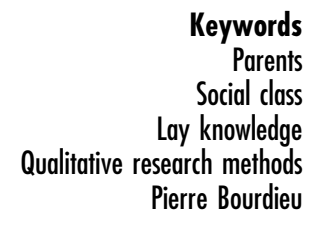

There is now a large body of evidence concerning the relationship between social structures and health. Indeed, under the heading 'Social determinants of health' can be found a burgeoning body of research - theoretical and empirical - emphasising the role social forces play in influencing the burden of disease in Western society. Much of the focus of this work concerns the origins and consequences of health inequalities in an attempt to better understand why individuals in higher socio-economic groups enjoy better health than those in lower groups. Importantly, this is not merely a comparison between the very poor and the very rich, the practice of which has a long and enduring history in public health ${ }^{1}$. Rather, what has become apparent is the existence of a health gradient across all social strata, not merely at the extremes ${ }^{2}$. To some extent this research direction can be seen as a counter-balance to an earlier emphasis on behavioural risk factors, which were often seen as merely a matter of individual choice. This focus has been criticised for failing to consider the social milieu in which individual choices are made. For example, work by Graham found that women in underprivileged circumstances used cigarette smoking as a coping measure to overcome the social pressures of managing families within limited resources ${ }^{3}$. Thus the examination of health-related behaviours is better informed when social circumstances are considered.

In Australia, a number of surveys have examined food in relation to social position, class or social prestige ${ }^{4-13}$. These comparative surveys have demonstrated that in Australia, as elsewhere, people from different social backgrounds shop differently, eat differently and have different food belief systems. While these insights have an important role to play in understanding food habits across social class, surveys - with pre-set questions and instruments - have a limited ability to gain a more indepth examination of the issues. Qualitative research, on the other hand, which seeks the viewpoint or stories of the 
respondents themselves, is more likely to yield richer insights ${ }^{14,15}$.

The notion of lay knowledge has been discussed in depth by Popay et al. ${ }^{16}$, who use it to represent the ways of speaking, or 'narratives', which represent the meanings and experiences influenced by the social circumstances in which people live. It is a more useful term than 'attitude' or 'beliefs' because it acknowledges the social milieu in which meaning and knowledge are constructed.

Some Australian studies have used qualitative research to provide in-depth understandings of food within particular social groups, e.g. low-income women ${ }^{17}$ and sole parents ${ }^{18}$. These studies are useful but, because of the focus on one particular group, limit our ability to compare findings across social class.

The Adelaide Food and Families Study reported here set out to contrast lay knowledge and eating habits of people from different social backgrounds. The study took a mainly qualitative approach to data collection with the explicit aim of attempting to understand the complexity of food practices within family life from the perspectives of the respondents. In doing so, it sought to examine lay explanations to provide insights into participants' lay knowledge.

One particular aim of the study was to examine the ways in which people from different social backgrounds draw on and use different forms of lay knowledge about food and health. Such an examination is very important because, while public health nutrition programmes (especially those with an education component) attempt to convey simplified messages, they do in many ways assume foundational scientific understandings and nutritional concepts. Studies have shown that these are not always shared across social class ${ }^{19}$. When this is the case the effectiveness of public health nutrition education programmes is limited, especially with those groups who experience greatest disease burden from diet-related illnesses such as low-income groups.

Qualitative research is undertaken primarily to understand and describe, and in doing so generate theories or explanations, rather than test hypotheses ${ }^{20}$. The present study was exploratory and results are not presented to prove conclusively a case for social class differences in lay knowledge. Rather, they are presented to encourage further research into and debate about the ways in which people's understandings of food and health vary according to social background, and what this might mean for public health nutrition.

\section{Materials and methods}

\section{The study}

Families were recruited to the Adelaide Families and Food Study from two different areas chosen on the basis of information from the Australian Bureau of Statistics. Area A was characterised by high numbers of low-income families, high levels of subsidised or housing trust accommodation, and low levels of tertiary education. Area B was characterised by the opposite profile households were mostly high-income, home ownership levels were high and tertiary education and professional qualifications were common.

\section{The sample}

Families were recruited to the study in the following way. Maps of the census collection districts (CCDs) in each area into were divided into six equal sections. A number between 1 and 6 was randomly selected (by the roll of a die) to select the section of each CCD for recruitment. All households in the selected section of each CCD received a letterbox-dropped invitation to join the study. This was followed up by a door-knock at each house to recruit suitable families. A family was deemed suitable if there were no more than four children living at home; at least one child was less than 12 years old; both mother and father lived at home; both parents agreed to be interviewed; and parents could communicate in English. The purpose of the selection criteria was to recruit socalled 'typical families', i.e. couples with young children, and to avoid duplicating studies that had already examined eating patterns in certain family types such as single-parent families ${ }^{18}$. In all, 20 families from each area (total of 40 families, 80 respondents) were recruited. No family dropped out of the study. The study was given ethics approval by the Ethics Committee in Flinders Medical Centre. Household income, home tenure and family profiles are provided in Table 1 .

\section{Methods}

The parents in each family were interviewed in their own home on three separate occasions by the author. A different range of issues was discussed during different visits. All interviews were audio-taped (with permission) and transcribed. Interview transcriptions were indexed,

Table 1 Household income*, home tenure and family profile in Areas $A$ and $B$

\begin{tabular}{|c|c|c|}
\hline & $\begin{array}{c}\text { Area A } \\
(n=20 \text { families })\end{array}$ & $\begin{array}{c}\text { Area B } \\
(n=20 \text { families })\end{array}$ \\
\hline $\begin{array}{l}\text { No. of families with annual } \\
\text { income }<A \cup \$ 20000\end{array}$ & 7 & 0 \\
\hline $\begin{array}{l}\text { No. of families with annual } \\
\text { income AU } \$ 20000-50000\end{array}$ & 8 & 1 \\
\hline $\begin{array}{l}\text { No. of families with annual } \\
\text { income }>\text { AU } \$ 50000\end{array}$ & 2 & 15 \\
\hline No. of families buying home & 6 & 19 \\
\hline $\begin{array}{l}\text { No. of families with parents } \\
\text { with university education }\end{array}$ & 1 & 17 \\
\hline $\begin{array}{l}\text { No. of families with at least } \\
\text { one child }<4 \text { years }\end{array}$ & 8 & 7 \\
\hline $\begin{array}{l}\text { No. of families with two } \\
\text { or fewer children }\end{array}$ & 12 & 15 \\
\hline
\end{tabular}

* Three families in Area A and four families in Area B declined to provide family income information. 
coded and managed using NUDIST version 4.0 (QSR Software, Melbourne, Australia), a package for handling qualitative data.

To guide the interviews a schedule was used. The schedule was piloted on two families (not included in the final sample) to ensure that the type, flow and number of questions were appropriate to the aims of the study. The final schedule consisted of open-ended questions about everyday routines around food preparation, shopping and other aspects of family food management and decisionmaking. Thus discussions ranged over a number of foodrelated issues. An overview of the areas addressed in the interviews is given in Table 2 .

Extensive field notes were recorded during data collection. Field notes are an important component of qualitative research, providing the opportunity for active reflection and in situ analysis of the data to highlight themes that arise. In light of this, the interview schedule was gradually modified during data collection to capture and explore emerging issues. However, a number of core questions about shopping, cooking and management of food in the home were asked of all families, partly to provide a structure to the interviews and partly to allow for comparisons between families and across Areas A and B.

The material presented in this paper is concerned with the ways in which the families responded to core questions, raised during the third and last interview,

Table 2 Areas addressed in interviews for the Adelaide Families and Food Study

Interview 1 - Food shopping and food storage in the home
Location of food shops
Distance to food shops
Means of getting to shops
Frequency of shopping for food
Time spent shopping
Aids to food shopping (e.g. lists, coupons)
Views on location and variety of shops
Budgeting for food shopping
Responsibility in the family for food shopping
Household inventory of storage facilities
Interview 2 - Family meal patterns and food preparation
Description of family meal patterns
Meals shared with others (friends, other family members)
Eating away from home as a family
Eating away from home as individuals (school/work lunches)
Cooking and food preparation
Influences on the family menu
Effects of food preferences of family members on food patterns
Social influences on meal patterns
Changes to family meal patterns over time
Any special arrangements to accommodate children
Interview 3 - Health, health information
and family food choices
Information sources about food and health
Influences of information about health on family food choices
Views on current information and advice about food and health
Views on what children eat
Views on what parents eat
Health problems that influence family food choice
Home production of food (e.g. garden produce)
Local (neighbourhood) food networks
Hown

which asked about children's eating habits. The responses to these questions were separated out of each family's transcript for examination and comparison. During the analysis special attention was paid to the language and concepts used in participants' explanations. In qualitative research increased rigour is often brought to analysis by an independent examination of the results (sometimes known as investigator triangulation ${ }^{21}$ ). In this study, triangulation was undertaken by mailing the relevant data to an observer (in Canada) who had had no prior contact with the study, and who was 'blind' to the social status of each Area. The observer was asked to read through the interview transcripts and identify whether different forms of lay knowledge could be identified and whether there was any association with Area. The observer's assessment of the data corresponded with that of the author.

The rest of this paper compares the ways in which participants discussed children's eating habits, with special attention to the differences between Areas A and B. The paper then examines the implications for public health nutrition.

\section{Results and discussion}

Parents raised a number of concerns about children's food preferences during the three interviews. Mainly these related to difficulties parents faced trying to cater to children's food tastes, and the impact this had on family food practices. This has been reported elsewhere ${ }^{22}$.

In relation to specific questions raised in the last interview about children's eating habits, marked differences between parents' responses in Areas A and B were noted. Responses from parents in Area B tended to be longer and more in-depth. However, there was also a major difference in the language and concepts used. For example, explanations from Area B parents were more likely to be in terms of the quality of the food, often described in technical language informed by nutritional science. Mostly this directly referred to the nutritional value of the food children did or did not eat. The examples below demonstrate this (emphasis added and all names used are pseudonyms):

\footnotetext{
'Lyn [daughter] is the most likely one to refuse her meat at the evening meal and I'm not worried from a nutritional kind of view because I know that she's eating, you know. Most of her sandwiches are either cheese sandwiches or peanut paste with the wholemeal bread, that's probably not bad.' (Mother, family \#2, Area B)
}

'I want them to enjoy eating but I don't know how much nutritional value, if any, or how bad, for instance, canned ravioli is.' (Mother, family \#15, Area B)

Occasionally reference to food values was couched in more descriptive language of food but still referring to 
nutritional values, as can be seen in this father's comments:

'But Craig doesn't have as much the way of green food, or the orange or yellow types of food.' (Father, family \#11, Area B)

More commonly, however, there was direct and overt reference to various nutritional components:

'Different nutrients from different things but I think again when you look at things overall I think they probably have a very adequate diet.' (Mother, family \#10, Area B)

It's a good sign that she [daughter] does like her fruit, so I feel a lot happier that she's getting her vitamins in, in the fruit intake, whereas she's missing out on vegetables, she does make up for it a certain extent with the fruit.' (Father, family $\# 9$, Area B)

Also of note was the focus for worry about children's diets. Area B parents' concerns about children's food were often related to specific illness or risk of disease:

'We're sort of giving her what we consider to be healthy foods, meat, fruit, vegetables, pasta, which are all supposed to be that fibrous stuff and all that, but in ten years they say, "Well actually this preservative has been added and your child is going to end up with a liver complaint or something".' (Mother, family \#14, Area B)

And discussions often included direct reference to medical conditions and syndromes, as this discussion between a father and mother indicates:

Father: 'You influence her [daughter] strongly and she responds very well.'

Mother: 'Because she understands about, she knows about girls who are anorexic and had bulimia. She's got a girl friend at school who's been a bulimia sufferer and she also doesn't want to be obese, so she listens, she does take notice. Because I've said, "You know, if you keep eating that way you'll just eat too many calories and you'll be fat and it's very hard to get rid of once you've got it on". And you can see her, she's happy with that now, she doesn't want to be obese.' (Father and mother, family \#16, Area B)

In contrast, parents in Area A rarely used nutritioninformed concepts in their responses. They were instead more likely to discuss children's eating habits in terms of children's outward physical appearance and general stamina. There was an overall assumption that because children grew, were happy and there were no outward signs of sickness, then they were eating well and healthy. The following excepts demonstrate this (emphasis added).

'...they are growing, you know I saw them growing well and I see them, they're eating.' (Mother, family \#6, Area A)

'They don't seem to get ill or anything very often, so I mean, obviously [we are] not doing anything too bad and that's pretty well what it is. They're both fairly bealthy, don't have too many problems, so we can't be doing too bad.' (Father, family \#9, Area A)

'The short answer to that question is that my kids aren't starving and they're obviously reasonably content in life, it doesn't worry me.' (Father, family \#11, Area A)

'But they are so atbletic see, they play football, they've both played football foryears and that. And the young fellow, like be has 4 Weetbix for breakfast and 4 bits of toast every morning, you know which is incredible.' (Father, family \#3, Area A)

When concerns were raised about their children's eating habits, parents in Area A also discussed them in terms of children's outward appearance. As one mother put it:

II think they [are] healthy kids. Maybe Ulrich [son] is not as bealthy because be looks chubbier but otherwise I don't really complain about the way they eat.' (Mother, family \#15, Area A)

Or in another family, a parent commented:

'You must control because you can't give a child everything she wants and especially [when] you see it goes on

ber body so the best way is to say no.' (Father, family \#18, Area A)

In sum, Area B high-income families were much more likely than Area A low-income families to advance explanations about children's eating habits in terms of nutrition and nutrients, and were more likely to relate to food as a health risk (e.g. obesity, damage to body systems). In Area A, parents rarely described food using technical nutritional descriptions. Instead, Area A parents were more likely to describe eating habits in relation to children's outward activity (growth, activity, etc.) or ability to play. A statistical analysis of responses would be inappropriate given the qualitative methodology employed in this study; however, the numerical differences can be described as follows. Thirteen of 20 Area B families employed a nutritionally informed response (compared with one of 20 families in Area A). Eight of 20 Area A families offered an outward activity-informed response (compared with two of 20 families in Area B). In qualitative research terms these differences are highly insightful in that they highlight different ways of expressing understandings about food and health.

In qualitative research, negative or disconfirming cases are deliberately used to examine the 'exceptions to the rule $^{, 23}$. Indeed, close examination of negative cases respondents who do not fit the overall picture for the whole group - can provide useful clues that may support or qualify the ways in which theories or hunches are interpreted. In this study, one family in low-income Area A was a negative case in that they articulated a more nutritional understanding about food with a direct reference to fat in the family diet. 
Interviewer: 'So generally how happy are you with the eating habits of your kids?'

Mother: (indistinct)

Interviewer: 'You're pulling a face Frank.'

Father: 'Mmm, I think our faces tell it all. We're not as happy as we'd like to be. We think we have to take more action on it.'

Mother: 'Even though we've in a way sort of reduced our fat intake and sometimes we, you know, it's a battle trying to..., yeah, we, it's sort of a battle with us with our eating habits, well I'm not really pleased with my eating habits.' (Mother and father, family \#20,Area A)

It so happened these participants worked in the community health service sector. Their responses therefore are more likely to be informed by professional experiences of health care; experiences which separate them from the other participants in Area A.

Overall then there was a marked difference in the responses by participants across social class, which was verified by an independent observer. Results from this research support findings elsewhere. For example, the study in the UK by Charles and Kerr found significant differences in women's responses about food and health across social class ${ }^{19}$. Similarly UK research by Calnan ${ }^{24}$, which compared attitudes to health, including diet, found that middle-class women were more likely to articulate a wider range of ideas and dietary components than working-class women. However, the study reported here demonstrates that these differences are not confined to women. In this research men from different class backgrounds also displayed different forms of lay knowledge about food and health.

It is well known that language use is intimately linked to social class $^{25}$ and whether the differences noted in this research simply reflect variations in idioms and language usage is hard to say. What is clear is that the middle-class respondents in Area B are more likely to share similar ideas and concepts about food and health with health professionals. These differences demonstrate the way that middle-class respondents' knowledge of diet connected with concepts of food (vitamins, fibre, risk of disease) that professionals often espouse. People from more working class backgrounds did not articulate these understandings, but instead tended to make reference to the outward, more functional aspects of food (growth, stamina, vitality). The data point to a difference in the lay knowledge that is used to inform understandings about food and health in various social classes.

Lay knowledge is now regarded as significant in its own right and not merely a set of quaint 'beliefs' subordinate to expertise or 'scientific' knowledge. For example, recent studies of health inequalities have found lay knowledge and lay theories (sometimes known as lay epidemiology $^{26}$ ) to be particularly illuminating in better understanding people's views on causality of health outcomes ${ }^{27}$.
In the same way, the present study provides an opportunity to appreciate different social understandings of food and health relationships.

Clues to the social basis of lay knowledge across social class can be drawn from the work of Pierre Bourdieu ${ }^{28,29}$. Bourdieu's large study of social class in France examined food within a social context and found that people from working class backgrounds were more likely to see food as a means of fuel and an immediate source of sustenance. They were also more likely to view the body as something to be used for (physical) work purposes, rather than aesthetically, i.e. strength rather than shape. Bourdieu used the term 'dispositions' to describe the ways in which individuals conceive of and view the world from their social position. Dispositions are constructed by a variety of social, cultural and material resources and experiences; they disposed individuals and groups towards particular attitudes, morals and expectations. The result is a class rationality or logic - a sense-making framework - that provides a foundation for lay knowledge. In Bourdieu's work it made sense (on the basis of current experiences) for working-class people, who were more likely to be involved in physical labour, to view the body as a machine and to see food as fuel for that machine. Middle-class groups were more likely to distinguish themselves by preferring to see the body as an aesthetic, cultural form, and see food as a matter of good taste and style. It is this distinction in the form of what Bourdieu calls "cultural capital' that allows one social group to have and exhibit its prestige over another. In terms of the findings of the present study, it is possible that the working-class parents saw food very much from a functional pragmatic point of view in terms of its effect on children's health. Middle-class parents were more inclined to express a scientific, more abstract, nutritionally informed understanding of food. This knowledge of food, and its articulation, may serve as a marker of social and educational privilege.

The consequences of 'disposition' are clear in other research findings on food and health. For example, Jain et $a l .{ }^{30}$ studied the attitudes of low-income mothers to children's weight problems. The mothers were suspicious of standard growth charts used by professionals to define obesity, did not see overweight as a problem so long as children were active and had good appetites, and blamed family tendencies as a major factor for children being overweight. In other words, for these parents, outward appearances were a convincing and a more rational basis for decision-making than abstract, scientific concepts of weight plotted on a graph. Cornwall's study of workingclass families in east London demonstrated that concepts of health are embedded in the daily experiences of the respondents $^{31}$. For many, there was a sense of fatalism about illness which individuals did not always have control over. Limited material resources may also make day-to-day family decision-making more focused on pragmatic survival issues ${ }^{32}$. On the other hand, Backett's 
study of health concepts in UK middle-class families showed that respondents were much concerned with an individual's responsibilities (so-called 'oughts') for their health behaviours ${ }^{33}$. This contrast could arguably represent the ways in which individuals in different social classes experience and perceive different degrees of control of resources and choices. Cornwall and Backett's work was carried out in the UK, where social class positions may be more distinctly recognised. However, Australia is far from 'classless' and the research presented here raises important implications for public health nutrition.

\section{Conclusions and implications for public health nutrition}

This paper has examined the lay knowledge of parents from different social backgrounds in relation to children's food and health. It highlights a relationship between social class and the different stocks of lay knowledge of food and health issues. The study is one of the first to suggest that class-based considerations of food and health issues are evident in men as well as women informants. Moreover, since this study was deliberately conducted in a family situation, where mothers and fathers were interviewed together in the home environment, the results come close to understanding a family context of food issues, as opposed to a more individual viewpoint. The theory developed in this research acknowledges an intellectual debt to the work of Bourdieu, which has been used by other researchers in food and nutrition ${ }^{34}$.

It should be noted that, along with other forms of research and data collection, qualitative research could conceal biases. Researcher bias has been addressed in this study through a reading of the relevant interview data by an independent observer, who supported the results discussed here. However, other forms of bias can occur. For example, conceivably the social differences discussed in this research could be the result of methodological artefact, especially the degree of comfort experienced by respondents of different social backgrounds when discussing eating habits with a university researcher. Noting the shared worldview between middle-class respondents and health professionals, it could be argued that the interviewer and the interview process, in some way, encouraged a greater articulation of nutritionally based information from families in Area B, or that families in Area A were less likely to open up. As mentioned earlier, middle-class suburb B parents participated in discussions to a greater degree. However, it is unlikely that families in Area A felt unable or unwilling to openly express themselves. The questions examined in this paper were put to the respondents in the last of three in-depth interviews (each lasting between 60 and $90 \mathrm{~min}$ ) with the same researcher. During each of the previous interviews, all carried out in the respondents' home, care was taken to establish rapport and to make it easy for participants to feel comfortable in discussions. The fact that no family withdrew from the study could be taken as an indication that participants felt at ease with the level and kind of questions. Moreover, that the findings of this study resonate with those from other research on health and social class is a further indication that the differences recorded here are not the results of a methodological artefact. It is likely therefore that the results are the product of social structures, backgrounds and lay knowledge of respondents.

The results of this study could be interpreted as demonstrating that respondents from Area B were simply more informed, better educated, better read and (therefore) more conversant with nutritional issues than were respondents from Area A. This may well be true since educational levels, university attendance and professional qualifications were higher in Area B (Table 1). The corollary of this for public health nutrition is, however, far from simple. Public health nutrition programmes, especially those with an educational component, have to address individuals, groups and communities from a variety of socio-economic backgrounds. And increasingly low-income groups have become something of a target ${ }^{35}$. However, public health nutrition education programmes have traditionally been based on an approach where health professionals deliver nutritional facts and concepts to passive lay audiences. This has been described as the 'injection' model of education ${ }^{36}$. The assumption behind this approach is that education, by virtue of its capacity to enlighten, informs and possibly emancipates those who hold illogical and unfounded knowledge and beliefs. It is based implicitly, and sometimes explicitly, on a belief that lay knowledge is inferior and needs correcting. This principle has a long history in nutrition education ${ }^{37}$. Recently, however, greater acknowledgement has been given to the importance of engaging with lay logic as it presents and on its own terms, rather than attempting to re-educate people to predetermined standards. In community development an approach termed 'assets-based inquiry' is a process that explicitly begins with a high regard for the resources already existing in a community be they intellectual, cultural or material - on which further capacity can be developed ${ }^{38}$. In organisational development the approach known as 'appreciative inquiry' is used in a similar way ${ }^{39}$. These approaches are similar to the work with indigenous communities, where pre-existing social and cultural knowledge and practices form the basis of health programmes. For example, the telling of appropriate stories, set in within the cultural milieu, has been integrated into nutrition education and used within Aboriginal communities ${ }^{40}$. The overall approach also resonates with emerging work on the use of narrative in nutrition counselling, where history-taking and decisionmaking develop from the client telling their story ${ }^{41}$. All these approaches are based, in one way or another, on an 
acceptance that there resides within individuals, organisations and communities logic and practical reason which is worthy of regard and as a useful starting point for participative inquiry ${ }^{42}$. This is not to argue that lay knowledge must remain unchallenged even when it appears to foster eating habits which do not promote health. It is to argue, instead, that for too long public health nutritionists have paid more attention to a universal, science-based understanding of food which they attempt to impart to clients and communities without an appreciation of lay knowledge, its social origins and the role it plays in structuring worldviews. There needs to be a recognition that different forms of knowledge co-exist, and that lay knowledge has a logic, a rationality and a sense-making basis, and is an important starting point for health improvement.

\section{Acknowledgements}

This research was funded by the National Health and Medical Council of Australia. I am indebted to Dr Elaine Power, Health Studies Program, School of Physical and Health Education, Queen's University Kingston, Ontario, Canada for independently reading and verifying the interview material used in this research, and for giving helpful feedback on early drafts of this paper. Thanks also to Catherine Palmer, Catherine Easterbrook, Bob Hughes, Gemma Ferraretto and two anonymous reviews for comments that improved the presentation of ideas in this paper.

\section{References}

1 Harris E, Nutbeam D, Sainsbury P. Does our limited analysis limit the way we seek solutions? In: Eckersley R, Dixon J, Douglas B, eds. The Social Origins of Health and Wellbeing. Melbourne: Cambridge University Press, 2001; 259-68.

2 Marmot M, Bosma H, Hemingway H, Brunner E, Stansfeld S. Contribution of job control and other risk factors to social variations in coronary heart incidence. Lancet 1997; 350: 235-9.

3 Graham H. Women, Health and the Family. Sussex: Wheatsheaf Books, 1984.

4 Baghurst K, Record S, Baghurst P, Syrette J, Crawford D, Worsley A. Sociodemographic determinants in Australia of food and nutrients implicated in cancer aetiology. Medical Journal of Australia 1990; 153: 444-52.

5 Steele P, Dobson A, Alexander H, Russell A. Who eats what? A comparison of dietary patterns among men and women in different occupational groups. Australian Journal of Public Health 1991; 15: 286-95.

6 Smith A, Baghurst K. Public health implications of dietary differences between social status and occupational category groups. Journal of Epidemiology and Community Health 1992; 46: 409-16.

7 Turrell G. Structural, material and economic influences on the food-purchasing choices of socio-economic groups. Australian and New Zealand Journal of Public Health 1996; 20: $611-7$.

8 Smith A, Baghurst K, Owen N. Socioeconomic status and personal characteristics as predictors of dietary change. Journal of Nutrition Education 1995; 27: 173-81.
9 Turrell G. Socioeconmic differences in food preferences and their influence on health food purchasing choices. Journal of Human Nutrition 1998; 11: 135-49.

10 Turrell G, Hewitt C, Patterson B, Oldenburg B, Gould T. Socioeconomic differences in food purchasing behaviour and suggested implications for diet-related health promotion. Journal of Human Nutrition and Dietetics 2002; 15: 355-64.

11 Mishra G, Ball K, Arbuckle J, Crawford D. Dietary patterns of Australian adults and their association with socio-economic status: results from the 1995 National Nutrition Survey. European Journal of Clinical Nutrition 2002; 56: 687-93.

12 Giske K, Turrell G, Patterson C, Newman B. Socioeconomic differences among Australian adults in consumption of fruit and vegetables and intakes of vitamins A, C and folate. Journal of Human Nutrition and Dietetics 2002; 15: $375-85$.

13 Giske K, Turrell G, Patterson C, Newman B. Socio-economic differences in fruit and vegetable consumption among adolescents and adults. Public Health Nutrition 2002; 5: 663-9.

14 Calnan M. Health and Illness: The Lay Perspective. London: Tavistock Publications, 1987.

15 Williams S, Calnan M. The 'limits' of medicalisation? Modern medicine and the lay populace in 'late' modernity. Social Science \& Medicine 1996; 42: 1609-20.

16 Popay J, Williams G, Thomas G, Gatrell A. Theorising inequalities in health: the place of lay knowledge. Sociology of Health and Illness 1998; 20: 619-44.

17 Santich B. It's a chore! Women's attitude towards cooking. Australian Journal of Nutriton and Dietetics 1995; 52: 11-3, 22.

18 Crotty P, Rutishauser I, Cahill M. Food in low-income families. Australian Journal of Public Health 1992; 16: $168-74$.

19 Charles N, Kerr M. Women, Food and Families. Manchester: Manchester University Press, 1988.

20 Rice P, Ezzy D. Qualitative Research Methods: A Health Focus. Melbourne: Oxford University Press, 1999.

21 Gifford S. Qualitative research: The soft option? Health Promotion Journal of Australia 1996; 6: 58-61.

22 Coveney J. The government of the table: nutrition expertise and the social organisation of family food habits. In: Germov J, Williams L, eds. A Sociology of Food and Nutrition: The Social Appetite, 2nd ed. Melbourne: Oxford University Press, 2004; 259-76.

23 Patton M. Qualitative Evaluation and Research Methods, 2nd ed. London: Sage, 1990.

24 Calnan M. Maintaining health and preventing illness: a comparison for the perceptions of women from different social class. Health Promotion 1986; 1: 167-77.

25 Romaine S. Language and social class. In: Smelser N, Bares P, eds. International Encyclopedia of the Social and Behavioural Sciences. New York: Elsevier, 2001; 8308-12.

26 Davidson C, Davy Smith G, Frankel S. Lay epidemiology and the prevention paradox: the implications of coronary candidacy for health education. Sociology of Health and Illness 1996; 13: 1-20.

27 Popay J, Bennett S, Thomas C, Williams G, Gatrell A, Bostock L. Beyond 'beer, fags and chips'? Exploring lay understandings of social inequities in health. Sociology of Health and Illness 2003; 25: 1-23.

28 Bourdieu P. Distinction: A Social Critique of the Judgement of Taste. London: Routledge and Kegan Paul, 1979.

29 Williams S. Theorising class, health and lifestyle: can Bourdieu help us? Sociology of Health and Illness 1995; 17: 577-604.

30 Jain A, Sherman SN, Chamberlin DL, Carter Y, Powers SW, Whitaker RC. Why don't low-income mothers worry about 
their preschoolers being overweight? Pediatrics 2001; 107: $1138-46$.

31 Cornwall J. Hard-earned Lives. London: Tavistock Publications, 1984.

32 Leinonen J, Solantaus T, Punamaki T. The specific mediating paths between economic hardship and the quality of parenting. International Journal of Behaviour Development 2002; 26: 423-35.

33 Backett K. Taboos and excesses: lay health moralities in middle-class families. Sociology of Health and Illness 1992; 14: $255-74$.

34 Power E. An introduction to Pierre Bourdieu's key theoretical concepts. Journal for the Study of Food and Society 1999; 3: 48-52.

35 Foley R, Pollard C, McGuiness D. Food Cent\$ - achieving a balanced diet on a limited budget. Australian Journal of Nutrition and Dietetics 1997; 54: 167-72.

36 Coveney J.. They need to be educated. In: Proceedings of the 11th National Conference Dietitians Association of
Australia. Canberra: The Dietitians Association of Australia, 1992.

37 Crotty P. Good Nutrition: Fact, Fashion in Dietary Advice. St Leonards, NSW: Allen and Unwin, 1995.

38 Kretzmann J. Building communities from the inside out. Shelterforce 1995; 17: 8-11.

39 Cooperrider DL, Srivastva S. Appreciative inquiry in organizational life. In: Woodman R, Pasmore W, eds. Research in Organizational Change and Development, vol. 1. Greenwich, CT: JAI Press, 1987.

40 Bear-Winfield R. Sharing Good Tucker Stories: A Guide for Aboriginal and Torres Strait Islander Communities. Canberra: Commonwealth Department of Health and Family Services, 1996.

41 Tapsell LC, Brenninger V, Barnard J. Applying conversation analysis to foster accurate reporting in the diet history interview. Journal of the American Dietetic Association 2000; 100: 818-24.

42 Heron J, Reason P. A participatory inquiry paradigm. Qualitative Inquiry 1997; 3: 274. 